\title{
Perceived Sexism as a Health Determinant in Spain
}

\author{
Carme Borrell, M.D., Ph.D., ${ }^{1,2,3}$ Lucia Artazcoz, M.D., M.P.H., Ph.D., ${ }^{1,3}$ Diana Gil-González, Ph.D., ${ }^{4}$ \\ Glòria Pérez, M.D., M.P.H., Ph.D.,, ${ }^{1,3}$ Izabella Rohlfs, M.D., Ph.D., ${ }^{3,5}$ and Katherine Pérez, M.P.H., Ph.D.,3
}

\begin{abstract}
Objectives: The goals of the present study are to explore the association between perceived sexism and selfperceived health, health-related behaviors, and unmet medical care needs among women in Spain; to analyze whether higher levels of discrimination are associated with higher prevalence of poor health indicators and to examine whether these relationships are modified by country of origin and social class.

Materials and methods: The study is based on a cross-sectional design using data from the 2006 Spanish Health Interview Survey. We included women aged 20-64 years $(n=10,927)$. Six dependent variables were examined: four of health (self-perceived health, mental health, hypertension, and having had an injury during the previous year), one health behavior (smoking), and another related to the use of the health services (unmet need for medical care). Perceived sexism was the main independent variable. Social class and country of origin were considered as effect modifiers. We obtained the prevalence of perceived sexism. Logistic regression models, adjusted for potential confounders, were fitted to study the association between sexism and poor health outcomes.

Results: The prevalence of perceived sexism was 3.4\%. Perceived sexism showed positive and consistent associations with four poor health outcomes (poor self-perceived health, poor mental health, injuries in the last 12 months, and smoking). The strength of these associations increased with increased scores for perceived sexism, and the patterns were found to be modified by country of origin and social class.

Conclusion: This study shows a consistent association between perceived sexism and poor health outcomes in a country of southern Europe with a strong patriarchal tradition.
\end{abstract}

\section{Introduction}

G ENDER DISCRIMINATION OR SEXISM can affect health to different degrees and by different pathways. Studies have shown for decades that women have often received inferior, insensitive treatment by public institutions and society in general. ${ }^{1}$ Indeed, sexism can introduce bias, since it may have an effect on such diverse activities as the recording of deaths and the characterization and recognition of physical and psychological health problems of women over time and in a wide range of countries. ${ }^{2}$ It has been suggested that the embodiment of experiences of discrimination can be a chronic stressor with long-term negative effects on health. ${ }^{3}$ The maximum expression of sexism is physical and mental violence, and gender violence, particularly intimate partner violence, is responsible for a considerable number of injuries and deaths worldwide. . $^{3,4,5,6}$
Gender discrimination is a form of social relationship between groups marked by the power of men and the subordination of women. In the rigid sexual division of social life, men have more power and social recognition, while women are relegated to positions of invisibility and are not assigned a social value. These positions of men and women have been legitimated over time, with their being considered as inevitable and appropriate, so that for centuries in Western countries transition to adult life has involved the commencement of paid or productive work for men, while for women it has involved marriage, motherhood, and what has been termed "reproductive work." Whereas productive work brings economic independence and full recognition of citizenship, reproductive work implies dependency and delegate citizenship.

The progressive incorporation of women into the labor market has had the effect of breaking down this traditional

\footnotetext{
${ }^{1}$ Agència de Salut Pública de Barcelona, Barcelona, Spain.

${ }^{2}$ Universitat Pompeu Fabra, Barcelona, Spain.

${ }^{3}$ CIBER Epidemiología y Salud Pública (CIBERESP), Spain.

${ }^{4}$ Universidad de Alicante, Alicante, Spain.

${ }^{5}$ Unitat de Planificació, CatSalut, Catalonia Health Department, Girona, Spain.
} 
social order. Nevertheless, in addition to facing greater unemployment, precarious contracts, and lower wages, ${ }^{8}$ women have to deal with pronounced gender segregation, of which both horizontal and vertical forms can be recognized. Horizontal segregation means that men and women have different occupations which typically results in women's being concentrated in a smaller range of occupations, especially in the services sector. Vertical segregation, on the other hand, refers to the fact that women typically occupy less-skilled positions with less authority and find their career advancement limited by a "glass ceiling."."

Over the last decade, increasing evidence supporting a relationship between discrimination and different health outcomes has been presented. Most studies have analyzed the impact of perceived discrimination on mental health, ${ }^{9,10,11}$ although some studies have focused on its impact on other health problems and issues, such as hypertension, healthrelated behaviors (smoking, alcohol consumption, and drug use), and the use of health services. $3,12,13,14,15,16$ Some studies have aimed to increase the visibility of discrimination against women and the absence or neglect of laws to eradicate this inequality. ${ }^{17}$ Few studies have analysed the association between sexism and health, and those that have addressed this issue have mainly been undertaken in the United States. ${ }^{3,14,17,18}$ Moreover, few scientific studies have examined the potentially different patterns of sexism and their relationship with health status by social characteristics such as ethnic group or socio-economic position. ${ }^{18}$

In Europe, research in this field is scarce and especially so in southern Europe, where very traditional gender attitudes still persist. The last Spanish Health Interview Survey (2006) included a measure of perceived discrimination for the first time. ${ }^{19,20}$ Given this situation, our objectives are, firstly, to explore the association between perceived sexism and selfperceived health, health-related behaviors, and unmet needs for medical care among women in Spain; secondly, to analyze whether higher levels of sexism are associated with a higher prevalence of poor health indicators; and, finally, to examine whether these relationships are modified by country of origin and social class.

\section{Material and Methods}

\section{Study population, and sample and data collection}

Data were taken from the 2006 Spanish Health Interview Survey, a cross-sectional survey based on a representative sample of the noninstitutionalized population. This survey used multiple-stage stratified sampling. First-stage units were census tracts, whereas second-stage units were family households. Within each household an adult (16 years or older) was selected to complete the questionnaire and, where applicable, one child (from 0 to 15 years). The selected sample included approximately 31,300 homes spread over 2,236 census tracts. The total number of people interviewed older than 16 years was 29,476. Data were collected through face-toface interviews at home between June 2006 and June 2007. ${ }^{21}$ Since the prevalence of perceived sexism among women aged 16-19 years and among those aged over 64 years was very low-9 cases for the group aged $16-19$ years $(1.1 \%)$, and 13 cases in those $>64$ years $(0.4 \%)$-the present analysis was restricted to women aged $20-64$ years $(n=10,927)$.

\section{Variables}

\section{Dependent variables}

Six dependent variables were considered: four were related to health status, one to health-related behaviors (smoking), and one to the use of health services. All these variables have been associated with discrimination ${ }^{3,13}$ except having had an injury, although, as Krieger noted, socially inflicted trauma (mental, physical) in society at large may be a pattern of embodying discrimination. ${ }^{3}$

- Self-reported health status was measured through a single question: "Would you say your overall health is very good, good, fair, poor, or very poor?" A dichotomous outcome variable was created $(1=$ fair, poor or very poor; $0=$ very good, good). This variable has been previously associated with morbidity and mortality. ${ }^{22}$

- Mental Health was measured by the 12 -item version of the General Health Questionnaire $(\mathrm{GHQ}-12){ }^{23}$ This screening instrument is widely used to detect risk of current, diagnosable psychiatric disorders. It focuses on breaks in normal functioning rather than on lifelong traits; therefore it covers personality disorders or patterns of adjustment when these are associated with distress. As recommended by the authors of the questionnaire, we used a two-point scoring method rating individuals as not having (0) or having (1) poor mental health. Individuals found to have total scores of 3 or more were classified as having poor mental health. ${ }^{24}$

- Hypertension was assessed through self-reporting and was elicited by a question about whether the respondent had suffered from hypertension during the previous year. This question was part of a list of 27 chronic conditions. Self-reported hypertension is a common form of assessment used in large-scale surveys in the absence of measured hypertension. It has proved to correlate well with medical records ${ }^{25,26}$ and with individual blood measurements. ${ }^{27}$

- Having had an injury during the year before the survey (yes, no).

- Smoking status grouped by those who have at some time smoked (daily, nondaily smokers, and past smokers) and nonsmokers.

- An unmet need for medical care was measured through the answer to the question: "In the last 12 months has there been any time when you needed medical care but could not get it?"

\section{Independent variables}

Sexism. Exposure to sexism was the main independent variable. We used a discrimination instrument based on Krieger, ${ }^{28}$ asking whether the interviewee had "during the last year experienced discrimination, been prevented from doing something or been hassled or made to feel inferior because of his/her sex, ethnicity or country of origin, educational level or social class, sexual orientation, or religion." If the answer was yes, they were then asked which of the types of discrimination referred to they had suffered in the following six situations: "at work, getting a job, at home (discriminated by his/her partner), at home (discriminated by others), getting medical care, in the street or other public setting." Answers were modeled as per a Likert scale: never, sometimes, often, constantly. Only 
$1 \%$ of the sample between 16 and 64 years of age did not answer this question. We considered a person to have experienced sexism if they felt they had been discriminated against on the grounds of their sex.

Hence, we obtained two measures: sexism: yes/no; and a summary score of frequency by adding all types of perceived sexism in any situation. "Sometimes" had a value of one, "often" a value of two, and "constantly" a value of three. The total sum of the scores ranged from zero (no discrimination) to 90 (if "constantly" was answered for the 6 situations in the 5 types of sexism). A score of 1 was attained in the case of $36.3 \%$ of discriminated women, a score of 2 in $23.6 \%, 3$ in $17.5 \%$, and more than 3 in $22.6 \%$. Based on these results, we created a four-level categorical variable: $0,1,2$, and 3 or more.

Social class and country of origin. In order to explore the different patterns of the relationship of sexism with health problems, we made a stratification through the introduction of social class and country of origin as effect modifier variables.

- Social class was assigned as a function of the highest occupation of all household members (respondent, partner or person with the highest salary in the household $)^{29,30}$ and measured with the widely used Spanish adaptation of the British Registrar General classification. ${ }^{31}$ Class I includes managerial and senior technical staff and freelance professionals; class II, intermediate occupations and managers in commerce; class III, skilled non-manual workers; class IV, skilled (IVa) and partly skilled (IVb) manual workers; and class V, unskilled manual workers. Because of the low number of individuals in some categories, the six original classes were merged into two groups: nonmanual (I, II, and III) and manual (IV and V).

- Country of origin was defined as the country or region of birth given by respondents. It was categorized as "Spanish"; "Another rich country" (Australia, Austria, Belgium, Canada, Denmark, Finland, France, Germany, Ireland, Italy, Japan, Republic of Korea, Ireland, Netherlands, Norway, Portugal, Sweden, Switzerland, United Kingdom, and the United States. These are EU15 countries and countries having a human development index $\geq 0.9^{32}$ ); or "A poor country" (all other countries). Because of the small sample size (2.1\% of all women) and the low prevalence of sexism reported by women from rich countries, the examination of the relationships between sexism and poor health outcomes by country of origin was limited to women born in Spain and poor countries.

Confounding variables. The categories included in the logistic regression models were:

- age

- marital status (single, married or cohabiting, widowed, divorced, or separated)

- employment status (working outside the house: yes/no)

- social support (assessed with the Duke profile,, 33,34 a measure of 11 statements that were scored using a fivecategory Likert scale, validated in Spain. ${ }^{35}$ These ranged from 1 (much less than desired) to 5 (as much as desired). The overall score was the sum of all responses
Table 1. Distribution of the Sample by Dependent and Independent Variables and Prevalence of Perceived Sexism in Women 20 to 64 Years of Age

\begin{tabular}{|c|c|c|c|}
\hline & $\%$ & $\begin{array}{c}\text { Prevalence } \\
\text { of sexism (\%) }\end{array}$ & $\mathrm{p}$ value \\
\hline \multicolumn{4}{|l|}{ Dependent variables } \\
\hline \multicolumn{4}{|l|}{ Self-perceived health status } \\
\hline Good & 67.0 & 3.3 & \\
\hline Poor & 33.0 & 3.7 & 0.217 \\
\hline \multicolumn{4}{|l|}{ Mental health status } \\
\hline Good & 70.6 & 2.5 & \\
\hline Poor & 23.6 & 6.7 & $<0.001$ \\
\hline Missing value & 5.8 & & \\
\hline \multicolumn{4}{|l|}{ Hypertension } \\
\hline No & 84.9 & 3.5 & \\
\hline Yes & 14.5 & 2.8 & 0.205 \\
\hline Missing value & 0.6 & & \\
\hline \multicolumn{4}{|l|}{ Injury } \\
\hline No & 91.2 & 3.2 & \\
\hline Yes & 8.8 & 5.3 & 0.001 \\
\hline \multicolumn{4}{|l|}{ Smoking } \\
\hline No & 53.4 & 2.8 & \\
\hline Current smoker & 30.1 & 4.2 & \\
\hline Exsmoker & 16.5 & 3.9 & $<0.001$ \\
\hline \multicolumn{4}{|l|}{$\begin{array}{l}\text { Unmet need for } \\
\text { medical care }\end{array}$} \\
\hline No & 94.6 & 3.3 & \\
\hline Yes & 5.4 & 5.4 & 0.007 \\
\hline \multicolumn{4}{|l|}{ Independent variables } \\
\hline \multicolumn{4}{|l|}{ Social class } \\
\hline I & 12.7 & 5.3 & \\
\hline II & 13.3 & 4.0 & \\
\hline III & 25.9 & 3.0 & \\
\hline IV & 38.8 & 3.2 & \\
\hline V & 8.1 & 2.0 & $<0.001$ \\
\hline Missing value & 1.2 & & \\
\hline \multicolumn{4}{|l|}{ Country of origin } \\
\hline Spain & 84.2 & 3.2 & \\
\hline Rich countries & 2.1 & 4.3 & \\
\hline Poor countries & 13.4 & 4.4 & 0.048 \\
\hline Missing value & 0.3 & & \\
\hline \multicolumn{4}{|l|}{ Age group } \\
\hline $20-29$ & 21.0 & 3.8 & \\
\hline $30-39$ & 25.8 & 4.4 & \\
\hline $40-49$ & 26.0 & 3.6 & \\
\hline \multirow{2}{*}{\multicolumn{4}{|c|}{ Marital status }} \\
\hline & & & \\
\hline Single & 27.1 & 4.6 & \\
\hline Married & 63.7 & 2.7 & \\
\hline Widowed & 2.9 & 1.0 & \\
\hline Separated, divorced & 5.9 & 6.9 & $<0.001$ \\
\hline Missing value & 0.4 & & \\
\hline \multicolumn{4}{|l|}{ Working status } \\
\hline No & 45.3 & 2.8 & \\
\hline \multirow{2}{*}{\multicolumn{4}{|c|}{ Social support (Duke profile)—quartiles }} \\
\hline & & & \\
\hline Q1 Less & 25.5 & 4.9 & \\
\hline Q2 & 21.5 & 4.2 & \\
\hline Q3 & 26.0 & 2.9 & \\
\hline Q4 More & 21.5 & 1.7 & $<0.001$ \\
\hline Missing value & 5.5 & & \\
\hline \multicolumn{4}{|l|}{ Body mass index } \\
\hline < 18.5 (low weight) & 2.7 & 5.4 & \\
\hline $18.5-<25$ (normal weight) & 53.0 & 3.9 & \\
\hline $25-<29$ (overweight) & 25.2 & 2.8 & \\
\hline$\geq 30$ (obesity) & 12.3 & 3.1 & 0.017 \\
\hline Missing value & 6.8 & & \\
\hline Total & 100.0 & 3.4 & \\
\hline
\end{tabular}

Number of cases not weighted: women $=12,337$ (415 declared perceived sexism). Number of weighted cases: 10,927.

$p$ value of the $\chi$-square test comparing the prevalence of sexism in the different groups. 
and was defined as "missing" when 5 or more items were not answered; the higher the score, the greater the social support)

- body mass index, defined as the declared weight (in kilograms)/declared height (in meters) ${ }^{2}$, was used to adjust the models where hypertension was the dependent variable. ${ }^{36}$ The BMI was categorized as $<18.5$ (low weight), 18.5 to $<25$ (normal weight), 25 to $<30$ (excess weight), $\geq 30$ (obesity), as proposed by the World Health Organization. ${ }^{37}$

\section{Data analysis}

All analyses included weights derived from the complex sample design. All variables were described (number of cases and percentages), and the prevalence of perceived sexism according to the independent variables was calculated.

As a first step, we described the prevalence of poor health outcomes by perceived sexism. In a second step we obtained the prevalence of these outcomes by social class and country of origin among women. Differences between the prevalence of poor health outcomes by a dichotomous variable recording the existence of perceived sexism or not were assessed with the $\chi$-square test. A $\chi$-square test of linearity was used to analyze the influence of perceived sexism when this was broken down into the four previously defined categories (summary score).

Multivariate logistic regression models were fitted to determine the associations (odds ratios, ORs) between poor health outcomes (six dependent variables) and perceived sexism, adjusting for age (continuous), marital status, ${ }^{38}$ working status, and social support (Duke profile in four categories). ${ }^{36,39}$ The hypertension model also included body mass index (BMI in four categories) as an adjusting variable ${ }^{36}$ and the unmet need for medical care model, which included self-perceived health (in two categories) ${ }^{40}$ as a controlling variable. In order to examine whether there was a significant increase in the OR of poor health status as the score of sexism increased, we also fitted models with this score expressed as a quantitative variable. In the next step of the analysis, four models for each dependent variable were fitted for the different categories of social class and country of origin (nonmanual from Spain, manual from Spain, nonmanual from poor countries, and manual from poor countries) in order to study whether the associations between perceived sexism and health outcomes changed in the different categories of social class and country of origin.

\section{Results}

Table 1 presents the distributions of study variables. More than half of the population belonged to nonmanual (I, II, III) social classes. A total of $13.4 \%$ of women were born in poor countries. Most women were classed as either single or married

The prevalence of perceived sexism was 3.4\% (372 cases). Perceived sexism was more prevalent in women from social classes I and II, in those from poor countries, in young women, in those who were separated or divorced, in those in employment at the time of the interview, and in those with less social support (Table 1).

Perceived sexism was associated with four health outcomes among women (poor self-perceived health, poor mental

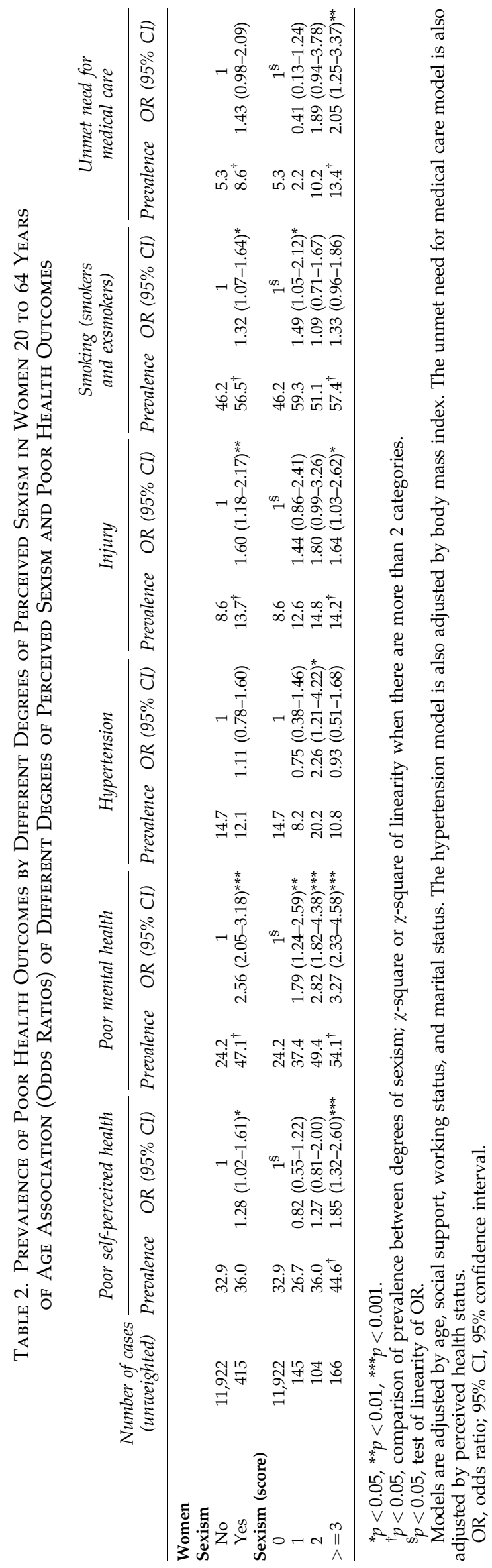


Poor self-perceived health

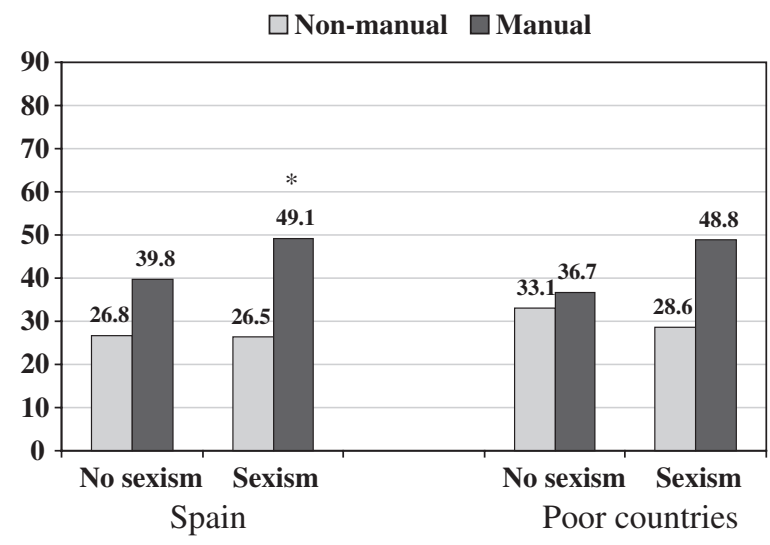

\section{Hypertension}

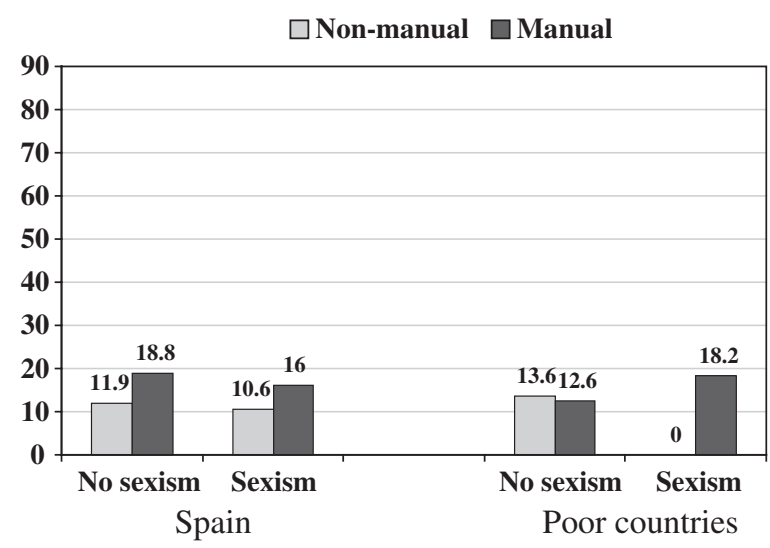

\section{Smoking}

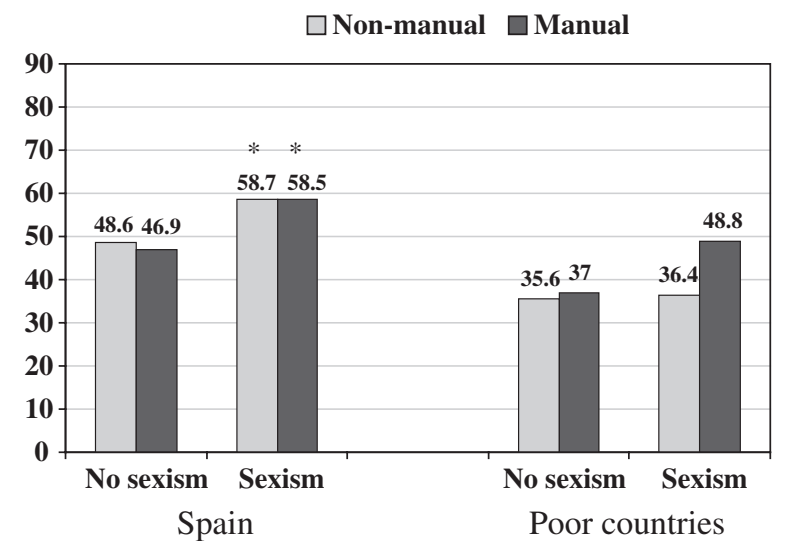

\section{Poor mental health}

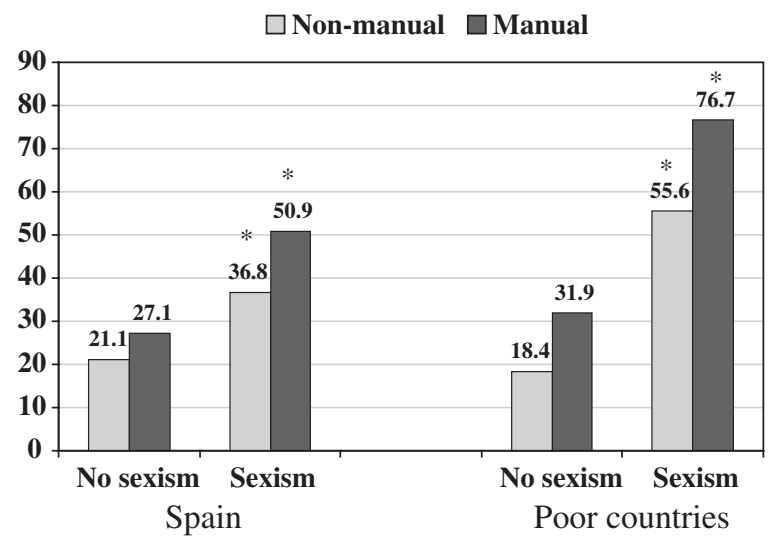

Injuries

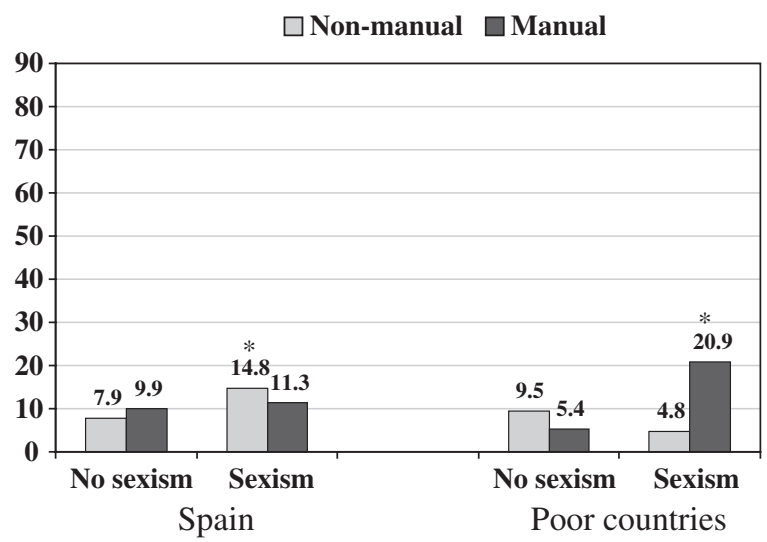

Unmet need for medical care

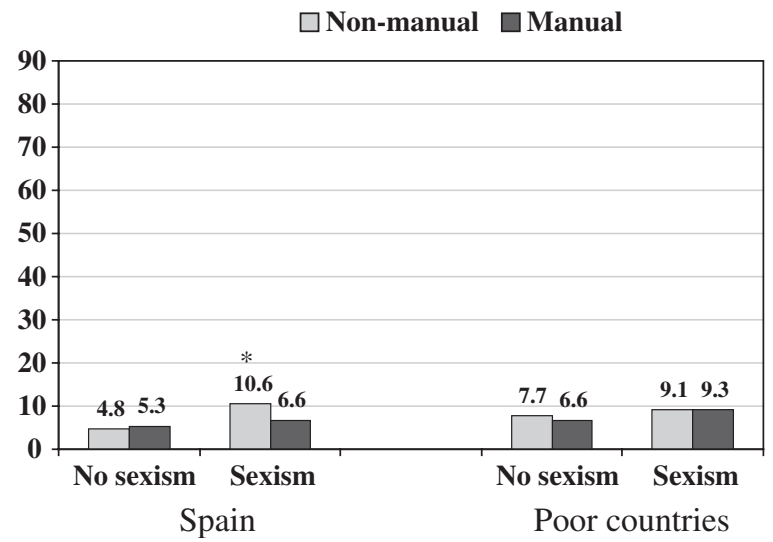

FIG. 1. Prevalence of poor health outcomes by perceived sexism in different groups of country-of-origin and social classes. Women 20-64 years of age. ${ }^{*} p<0.05$ (comparison of prevalence between those perceiving and those not perceiving sexism) ( $\chi$-square)

health, injuries during the previous twelve months, and smoking) (Table 2). The strongest association occurred with poor mental health (adjusted OR $=2.56,95 \% \mathrm{CI}: 2.05-3.18$ ). Except in the case of hypertension, it was found that for all dependent variables, the higher the score of sexism, the poorer the health outcome, and the higher the prevalence and the values of the odds ratios.
The prevalence of poor health outcomes by perceived sexism by country of origin and social class in women is presented in Figure 1. The prevalence of poor self-perceived health and poor mental health was higher among women from manual classes and women who perceived sexism, mainly from poor countries. The prevalence of injuries was higher for nonmanual-class women from Spain who 
perceived sexism and also for manual-class women from poor countries who perceived sexism. Among Spaniards, there were no differences in smoking by social class, but the prevalence was much higher among those who perceived sexism.

Table 3 presents the associations between perceived sexism and poor health outcomes in the four groups of women, depending on their country of origin and social class. Poor selfperceived health was associated with perceived sexism only in Spaniards from manual classes. Poor mental health was found to be associated in the four groups of women with stronger associations among women from poor countries. Injuries were associated with perceived sexism in nonmanual Spanish women and in manual women from poor countries. Smoking was associated in Spanish women (nonmanual and manual social classes), and unmet need for medical care was only associated among Spanish women from nonmanual social classes.

\section{Discussion}

The main findings of our study are as follows: (a) perceived sexism was higher among women of social classes I-II and migrants from poor countries; (b) perceived sexism showed positive and consistent associations with four poor health outcomes (poor self-perceived health, poor mental health, injuries in the previous twelve months, and smoking); (c) these associations became stronger as the score of perceived sexism increased: the greater the degree of perceived sexism, the greater the prevalence of poor health outcomes; and (d) these patterns were modified by country of origin and social class.

To the best of our knowledge, this is the first study of sexism and health carried out in a southern European country. Moreover, it is based on a large representative sample of the country, examines a broad range of health outcomes, and considers the roles of country of origin and social class.

\section{Prevalence of sexism}

An interesting finding was the low prevalence of selfperceived sexism among women as compared with other studies in which higher percentages of women reported that they had experienced sexism in the previous year. ${ }^{41}$ Several factors relating to the Spanish social context could help to explain the low levels of perceived sexism in this country. At the beginning of the twentieth century, Spain was relatively advanced in the recognition of women's rights, which included the right to vote, to get divorced, and to abort legally. These rights were curtailed with the establishment of the dictatorship of Franco (1939-1975): political parties and trade unions were made illegal, the recognition of civil liberties was suspended, and women were relegated to household roles, with their rights being subordinated to those of men. ${ }^{42}$ Not until more than 30 years later, following the death of the dictator, would some recovery of civil and women's rights begin. One change that had a considerable impact was the General Law of Education in $1970 .{ }^{43}$ This formed the basis for compulsory education and allowed coeducation, which had until that time been forbidden. In 1977, the new Spanish Constitution was voted in; in 1978 the use of oral contraception was legalized; ${ }^{44}$ and in 1985 a partial decriminalization of induced abortion was approved, ${ }^{45}$ which by 2010 has broadened social attitudes. Since the end of the dictatorship, the incorporation of women into the labor market has increased considerably, ${ }^{46,47}$ as has their participation in society in general. However, the expectations of Spanish women regarding their role in society after this long period of marked gender inequalities are likely to be lower than in other neighboring countries because of their socialization, resulting in a legitimization of sexism by which the majority of women internalized or denied its existence.

What is meant by discrimination depends on social, cultural, and economic characteristics, as well as on social class and the country of origin of women, which together configure their expectations as to their role in society. Declared sexism was higher among women of advantaged social classes, as has been found in other studies. It is possible that women of the manual social class are less aware of sexism than women of nonmanual classes, ${ }^{48}$ while nonmanual women possibly have a higher probability of not reaching their professional expectations because of the "glass ceiling," a fact that could also partially explain the higher levels of sexism reported by the youngest women. Moreover, there is an increasing awareness of sexism among young women who did not live under the dictatorship.

At the end of the twentieth century, a new wave of foreign immigration to Spain began, mainly from poor countries and for economic reasons, with the rate increasing markedly at the beginning of the twenty-first century. ${ }^{49}$ This population usually has worse living and working conditions, a fact that might explain the higher percentages of perceived discrimination among women from poor countries. In these cases, two axes of inequality are operating (gender and poor country of origin). A study carried out in Memphis, Tennessee, showed a complex relationship between socioeconomic status, race, and perceived discrimination among healthy women. The majority of white and black women $(60 \%)$ reported gender discrimination, but a higher percentage of white women reported perceiving only gender discrimination (38\% vs. $8 \%$ ) and not other types of discrimination. Another interesting result was that women with higher education declared more discrimination. ${ }^{50}$

\section{Perceived sexism and health outcomes}

The associations between gender discrimination and poor mental health found in this study are consistent with studies conducted in other countries. ${ }^{3,12,13}$ Mental health is the most extensively studied health outcome related to discrimination, ${ }^{13,15,16}$ although few studies have focused solely on sexism. As Krieger and Wamala et al. state, the embodiment of experiences of discrimination expressed through poor mental health can be explained because perceiving discrimination provokes fear and anger and becomes a chronic stressor in the long run. ${ }^{3,51}$ One study has reported that sexism is independently associated with various health indicators in women, after controlling for other traditional stressors. ${ }^{52}$ Apart from this direct link, among women sexism could be linked indirectly to mental health problems through exposure to the poor conditions of life and work, mainly among women of poor countries. Parker and Griffin described that the relationship between gender harassment in women working in traditionally male occupations and psychological distress may be mediated by overperformance demand, which implies that 


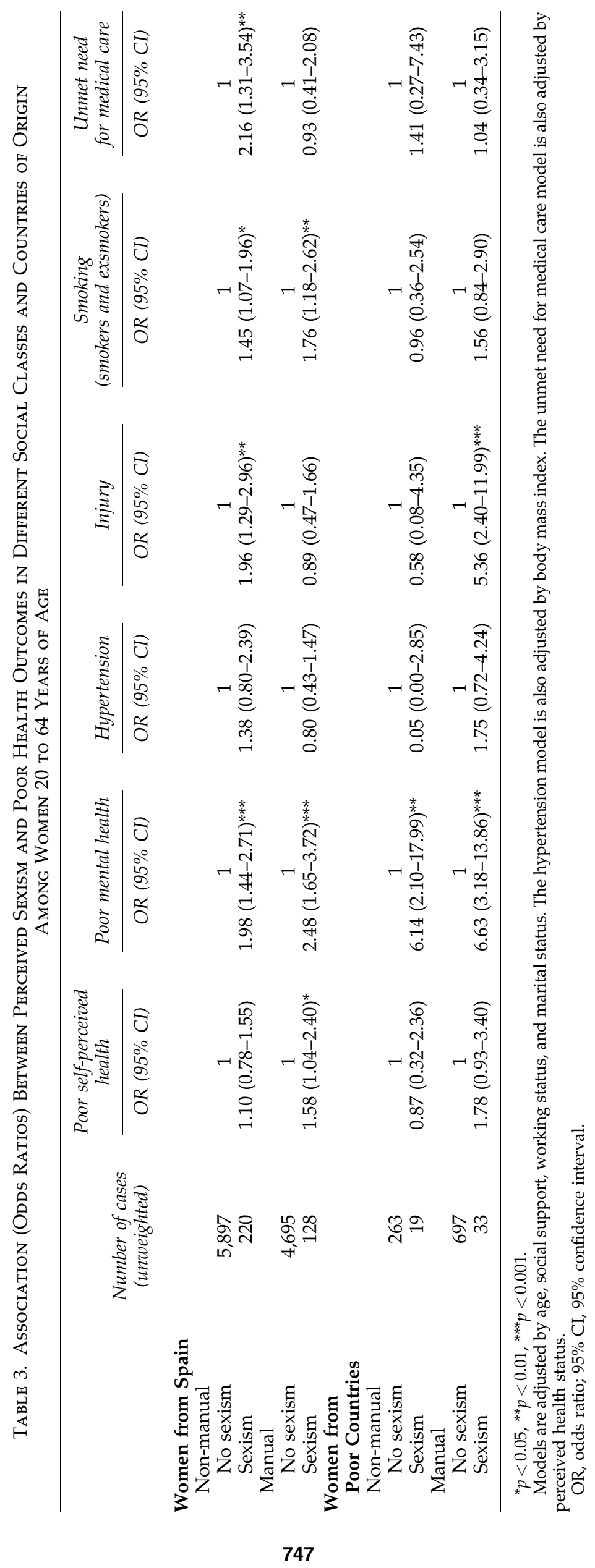


these women need to overperform to gain acceptance and recognition within the workplace, resulting in excessive effort. ${ }^{10}$ In our study, $53.1 \%$ of women who declared sexism said that they experienced it at work.

Besides the association we found with poor mental health, an outcome observed by other studies, the present study also analyzed the association of sexism with a variety of other health outcomes that have not been previously analyzed. ${ }^{53}$ First of all, hypertension was not associated with perceived sexism. This result is consistent with other studies that have not found a positive association between discrimination and hypertension. In the Paradies review of racism and health, 59 of the 79 studies where hypertension was analyzed failed to find an association. ${ }^{13}$

Injuries were related to perceived sexism in nonmanualclass Spanish women and in manual women of poor countries. Injuries in discriminated women occurred mostly at home, particularly among manual-class women of poor countries who perceived sexism (almost 8 out of 10 injuries at home, but 4 out of 10 among those who had not perceived sexism).

In Spain, smoking has increased among Spanish women and currently is increasing among young people, with smoking prevalence now being higher particularly among women and men of deprived social classes. ${ }^{54,55}$ Smoking was associated with perceived sexism in Spanish women, as has been reported in studies about racial discrimination in the United States. ${ }^{56,57}$ Smoking can be a mechanism to cope with the stress of perceived gender discrimination.

In our study, nonmanual-class women from Spain who perceived sexism had a higher prevalence of unmet need for medical care. One U.S. study associated gender discrimination with nonadherence to mammography screening among women with high income. Life stressors in these women, such as sexism, may therefore adversely affect the use of potentially beneficial preventive health programs. ${ }^{48}$

\section{Limitations of the study}

This study is limited by its cross-sectional design that prevents inferring the direction of relationships, and we cannot exclude the possibility that the perception of sexism might have been influenced by prior health status (particularly mental health). ${ }^{58}$ However, the results found are very consistent across many poor health outcomes and different population groups. Additionally, the higher the score of sexism, the greater the prevalence of poor health outcomes. Moreover, some prospective studies have also described the association between perceived discrimination and poor mental health. ${ }^{59}$ As has been mentioned before, the low prevalence of perceived sexism in our study can be explained by the social and cultural characteristics of Spain, but we cannot rule out underreporting related to the insufficient adaptation of the instrument used to measure sexism in the Spanish context. Future studies should improve the measure of gender discrimination to overcome this potential limitation. $^{60}$

\section{Conclusions}

This study has shown a consistent association between perceived sexism and poor health outcomes in a country of southern Europe with strong patriarchal traditions. The im- plications of our findings go beyond the healthcare system and point to the need for considering health in all policy areas. The fact that sexism in different settings can cause a wide range of health problems makes it essential to consider health consequences in drawing up and implementing antigender discrimination policies. Given the interest of these results in better understanding the impact of sexism on health outcomes, it is to be hoped that similar studies will be undertaken in other countries sharing comparable social and cultural characteristics.

\section{Acknowledgments}

This study was partially funded by CIBER Epidemiología y Salud Pública, Spain; by the Ministerio de Sanidad y Consumo-Observatorio de Salud de la Mujer, Dirección General de la Agencia de Calidad-y Ministerio de Ciencia e Innovación-Instituto de Salud Carlos III, Spain; and by the project "Analysis of the Effects of Discrimination in the Selfperceived Health in Adult and Children Populations in Spain" from the Fondo de Investigación Sanitaria" of the latter institutions (reference PI080782).

\section{Disclosure Statement}

The authors have no competing financial interests to report.

\section{References}

1. Weaver JL, Garrett SD. Sexism and racism in the American health care industry: a comparative analysis. Int J Health Serv 1978;8:677-703.

2. Clarke J.N. Sexism, feminism and medicalism: a decade review of literature on gender and illness. Sociol Health Illness 1983;1:62-82.

3. Krieger N. Discrimination and health. In: Berckman L, Kawachi I., eds. Society and health. Oxford: Oxford University Press, 2000:36-75.

4. Krieger N. Genders, sexes, and health: what are the connections-and why does it matter? Int J Epidemiol 2003; 32:652-654.

5. WHO Multi-country study on women's health and domestic violence against women. Geneva, Switzerland: WHO, 2005. www.who.int/gender/violence/who_multicountry_study/ en/index.html Accessed June 15, 2009.

6. Blanco P, Ruiz-Jarabo C, Garcia de Vinuesa L, MartinGarcia M. La violencia de pareja y la salud de las mujeres. In: Borrell C, García-Calvente MM, Martí-Boscà V, eds. Informe SESPAS 2004. La salud pública desde la perspectiva de género y clase social. Gac Sanit. 2004;18(Suppl 1):182188.

7. Artazcoz L, Borrell C, Cortès I, Escribà-Agüir V, Cascant L. Occupational epidemiology and work related inequalities in health: a gender perspective for two complementary approaches to work and health research. J Epidemiol Community Health 2007;61(Suppl 2):ii39-45.

8. Paoli P, Merllié D. Third European survey on working conditions, 2000. Luxembourg: Office for Official Publications of the European Communities, 2001.

9. Piotrkowski CS. Gender harassment, job satisfaction, and distress among employed white and minority women. J Occup Health Psychol 1998;3:33-43.

10. Parker SK, Griffin MA. What is so bad about a little namecalling? Negative consequences of gender harassment for 
overperformance demands and distress. J Occup Health Psychol 2002;7:195-210.

11. Llácer A, Amo JD, García-Fulgueiras A, et al. Discrimination and mental health in Ecuadorian immigrants in Spain. J Epidemiol Community Health 2009;63:766-772.

12. Williams DR, Neighbors HW, Jackson JS. Racial/ethnic discrimination and health: findings from community studies. Am J Public Health 2003;93:200-208. Review.

13. Paradies Y. A systematic review of empirical research on self-reported racism and health. Int J Epidemiol 2006;35:888901.Review.

14. Krieger N, Rowley DL, Herman AA, Avery B, Phillips MT. Racism, sexism, and social class: implications for studies of health, disease, and well-being. Am J Prev Med 1993; 9(6 Suppl):82-122. Review.

15. Williams DR, Mohammed SA. Discrimination and racial disparities in health: evidence and needed research. J Behav Med 2009;32:20-47. Review.

16. Pascoe EA, Smart Richman L. Perceived discrimination and health: a meta-analytic review. Psychol Bull 2009;135:531554.

17. Thurshen M. The impact of sexism on women's health and health care. J Public Health Policy 1993;164-173.

18. Ro, AE. Choi, K-H. Social status correlates of reporting gender discrimination and racial discrimination among racially diverse women. Women Health 2009;49:1-15.

19. Rohlfs I, Borrell C, Artazcoz L, Escribà-Agüir V. The incorporation of gender perspective into Spanish health surveys. J Epidemiol Community Health 2007;61(Suppl 2): ii20-25.

20. Borrell C, Muntaner C, Benach J, Artazcoz L. Social class and self-reported health status among men and women: what is the role of work organisation, household material standards and household labour? Soc Sci Med 2004;58:1869-1887.

21. Ministerio de Sanidad y Consumo. Metodologia de la Encuesta Nacional de Salud de 2006. www.msc.es/estadEstudios/ estadisticas/encuestaNacional/encuesta2006.htm Accessed July 15, 2009.

22. Idler EL, Benyamini Y. Self-rated health and mortality: a review of twenty-seven community studies. J Health Social Behav 1997;38,1:21-37.

23. Goldberg D. The detection of psychiatric illness by questionnaire. Oxford, U.K.: Oxford University Press, 1972.

24. Goldberg D. Manual of the general health questionnaire. Windsor, U.K.: NFER Publishing, 1978.

25. Kehoe R, Wu SY, Leske MC, Chylack LT. Comparing selfreported and physician-reported medical history. Am J Epidemiol 1994;139:813-818.

26. Okura Y, Urban LH, Mahoney DW, Jacobsen SJ, Rodeheffer RJ. Agreement between self-report questionnaires and medical record data was substantial for diabetes, hypertension, myocardial infarction and stroke but not for heart failure. J Clin Epidemiol 2004;57:1096-1103.

27. Vargas CM, Burt VL, Gillum RF, Pamuk ER. Validity of selfreported hypertension in the National Health and Nutrition Examination Survey III, 1988-91. Prev Med 1997; 26: 678685.

28. Krieger N, Smith K, Naishadham D, Hartman C, Barbeau EM. Experiences of discrimination: validity and reliability of a self-report measure for population health research on racism and health. Soc Sci Med 2005;61:1576-1596.

29. Krieger N, Chen JT, Selby JV. Comparing individual-based and household-based measures of social class to assess class inequalities in women's health: a methodological study of
684 US women. J Epidemiol Community Health 1999;53: 612-623.

30. Borrell C, Rohlfs I, Artazcoz L, Muntaner C. [Inequalities in health related to social class in women. What is the effect of the measure used?] Gac Sanit. 2004;18(Suppl 2):75-82.

31. Grupo SEE y Grupo SEMFYC. Una propuesta de medida de la clase social. Aten Primaria. 2000;25:350-363.

32. Human Development Report, 2007/2008. Fighting climate change: human solidarity in a divided world. New York: United Nations Development Programme, 2007a. Available at http://hdr.undp.org Accessed June 15, 2009.

33. Measures of social support. In: Wilkin D, Hallam L, Dogget $\mathrm{M}$, eds. Measures of need and outcome for primary health care. Oxford, U.K.: Oxford University Press, 1992.

34. Broadhead WE, Gehlbach SH, Degruy FV, Kaplan BH. The Duke-UNC functional social support questionnaire: measurement of social support in family medicine patients. Med Care. 1988;26:709-23.

35. Bellón JA, Delgado A, Luna JD, Lardelli P. Validez y fiabilidad del cuestionario de apoyo social funcional Duke-UNC11. Aten Primaria 1996;18:153-162.

36. Roberts CB, Vines AI, Kaufman JS, James SA. Crosssectional association between perceived discrimination and hypertension in African-American men and women: the Pitt County Study. Am J Epidemiol 2008;167:624-632.

37. World Health Organization. BMI classification. Available at http://apps.who.int/bmi/index.jsp?introPage=intro_3.html Accessed July 21, 2009.

38. Arber S. Comparing inequalities in women's and men's health: Britain in the 1990's. Soc Sci Med 1997;44:773787.

39. Borrell LN, Jacobs DR Jr, Williams DR, Pletcher MJ, Houston TK, Kiefe CI. Self-reported racial discrimination and substance use in the coronary artery risk development in adults study. Am J Epidemiol 2007;166:1068-1079.

40. Wamala S, Merlo J, Boström G, Hogstedt C. Perceived discrimination, socioeconomic disadvantage and refraining from seeking medical treatment in Sweden. J Epidemiol Community Health 2007;61:409-415.

41. Klonoff EA, Landrine H, Campbell R. Sexist discrimination may account for psychiatric symptoms. Well-known gender differences in psychiatric symptoms. Psychol Women Q 2000;24:93-99.

42. Navarro V, Shi L. The political context of social inequalities and health. Soc Sci Med 2001;52:481-491.

43. Ley General de Educación [General Law of Education]. Boletín Oficial del Estado, Ley 14/4 1970 (August 4).

44. Ley de despenalización del uso contraceptivo de la píldora anticonceptiva [Law of decriminalization of oral contraception]. Boletin Oficial del Estado, Ley 45/7 1978 (October 7).

45. Ley orgánica de despenalización del aborto en determinados supuestos [Law of decriminalization of induced abortion]. Boletín Oficial del Estado, Ley 9, 1985 (July 5).

46. Artazcoz L, Escribà-Agüir V, Cortès I. [Gender, paid work, domestic chores and health in Spain]. Gac Sanit 2004;18 (Suppl 2):24-35. Review.

47. Morant, I. Historia de las mujeres en España y América latina IV. Del siglo XX a los umbrales del XXI. Madrid: Ed. Cátedra, 2005.

48. Dailey AB, Kasl SV, Jones BA. Does gender discrimination impact regular mammography screening? Findings from the race differences in screening mammography study. J Women's Health 2008;17:195-206. 
49. Instituto Nacional de estadística (INE). Available at www.ine.es Accessed June 5, 2009.

50. Watson JM, Scarinci IS, Klesges RC, Slawson D, Beech BM. Race, socioeconomic status and perceived discrimination among healthy women. J Women's Health Gend Based Med 2002;11:441-451.

51. Wamala S, Boström G, Nyqvist K. Perceived discrimination and psychological distress in Sweden. Br J Psychiatry 2007;190:75-76.

52. Landrine H, Klonoff EA, Gibbs J, Manning V, Lund M. Physical and psychiatric correlates of gender discrimination: an application of the schedule of sexist events. Psychol Women Q 1995;19:473-492.

53. Krieger N, Chen JT, Waterman PD, et al. The inverse hazard law: blood pressure, sexual harassment, racial discrimination, workplace abuse and occupational exposures in US low-income black, white and Latino workers. Soc Sci Med 2008;67:1970-1981.

54. Giskes K, Kunst AE, Benach J, et al. Trends in smoking behaviour between 1985 and 2000 in nine European countries by education. J Epidemiol Community Health 2005;59:395-401.

55. Villalbí JR, Rodríguez-Sanz M, Villegas R, Borrell C. [Changes in the population smoking patterns: Barcelona, 1983-2006]. Med Clin 2009;28:132:414-419.

56. Landrine $\mathrm{H}$, Klonoff EA. Racial discrimination and cigarette smoking among blacks: findings from two studies. Ethn Dis 2000;10:195-202.
57. Chae DH, Takeuchi DT, Barbeau EM, Bennett GG, Lindsey J Krieger N. Unfair treatment, racial/ethnic discrimination, ethnic identification, and smoking among Asian Americans in the national latino and Asian American study. Am J Public Health 2008;98:485-492.

58. Alonso J, Buron A, Bruffaerts R, et al. Association of perceived stigma and mood and anxiety disorders: results from the world mental health surveys. Acta Psychiatr Scand 2008;118:305-314.

59. Schulz AJ, Gravlee CC, Williams DR, Israel BA, Mentz G, Rowe Z. Discrimination, symptoms of depression, and selfrated health among African American women in Detroit: results from a longitudinal analysis. Am J Public Health 2006;96:1265-1270.

60. Masser B, Abrams D. Contemporary sexism. The relationships among hostility, benevolence and neosexism. Psychology Women Q 1999;23:503-517.

Address correspondence to: Carme Borrell, M.D., Ph.D. Agència de Salut Pública de Barcelona Plaça Lesseps 1, 08023, Barcelona Spain

E-mail: cborrell@aspb.cat 